This is the author's version (post-print) of the work that was accepted for publication in the proceedings of the AIAA Aviation Forum held online, June 2020.

(C2020. This manuscript version is made available under the CC-BY-NC-ND 4.0 license;

http://creativecommons.org/licenses/by-nc-nd/4.0/

The final version was published in the proceedings of the conference as paper No. 2020-2566.

https://doi.org/10.2514/6.2020-2566

\title{
Estimation of turbulence in fan-rotor wakes for broadband noise prediction during acoustic preliminary design
}

\author{
Robert Meier zu Ummeln* and Antoine Moreau ${ }^{\dagger}$ \\ German Aerospace Center (DLR), 10623 Berlin, Germany
}

\begin{abstract}
When calculating broadband fan noise caused by rotor-stator wake interaction analytically, information about the airflow, particularly about the turbulence in the rotor wakes, is necessary. During the pre-design phase, two-dimensional streamline methods are commonly used. These provide only general flow quantities like mean-flow velocities or total-pressure losses. Turbulent parameters such as turbulent kinetic energy and turbulent integral length scale need to be deduced from these quantities. There are several models mentioned in the literature which correlate the wake size with the wake turbulence. But they usually comprise calibration factors that need to be assessed empirically by numerical simulations or measurements. The contribution of the paper is to present an updated semi-empirical model for rotor-wake turbulence quantities, derived on the basis of an extensive comparison of the model with measurements and numerical simulations on four different turbofan stages. A recalibration of the empirical factors improved the noise prediction by $8 \mathrm{~dB}$, reaching an accuracy of $2 \mathrm{~dB}$. In addition, it is shown, that the endwall flow is responsible for large variance in the noise prediction, and may have a contribution of up to $2 \mathrm{~dB}$ to the overall sound power.
\end{abstract}

\section{Nomenclature}

$A=$ normalized wake area $[-]$

$c \quad=$ profile chord length $[\mathrm{m}]$

$c_{D}=$ drag coefficient $[-]$

$d \quad=$ normalized wake depth $[-]$

$f \quad=$ frequency $[1 / s]$

$f_{x}=$ ratio of two quantities explained in the paper [-]

$h=$ wake harmonic order $[-]$

$h_{l} \quad=$ streamtube height $[\mathrm{m}]$

$H_{12}=$ boundary-layer shape factor [-]

$I=$ turbulent intensity $[-]$

$k=$ turbulent kinetic energy (TKE) $\left[\mathrm{m}^{2} / \mathrm{s}^{2}\right]$

$K_{U}=$ empirical constant for estimation of turbulent kinetic energy [-]

$K_{L}=$ empirical constant for estimation of turbulent integral length scale [-]

*Research Engineer, Department of Engine Acoustics, Robert.MeierzuUmmeln@dlr.de.

${ }^{\dagger}$ Research Engineer, Department of Engine Acoustics, Antoine.Moreau@ dlr.de. 


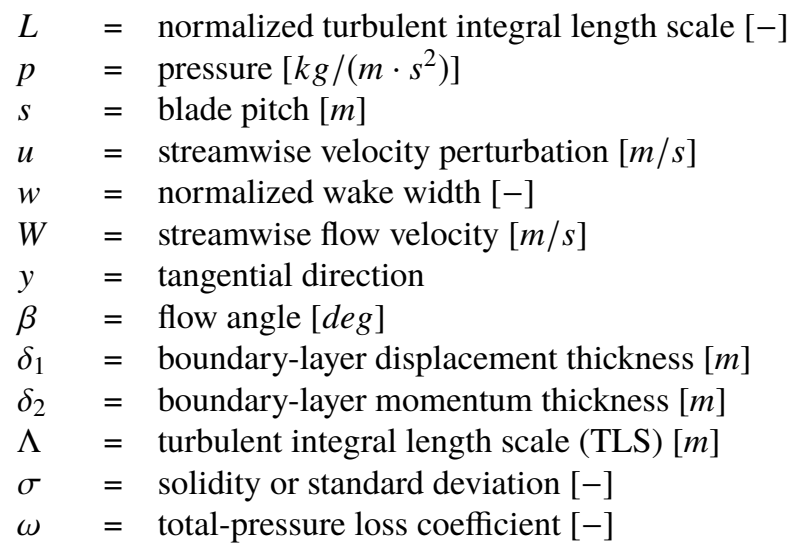

\section{Introduction}

$\mathrm{T}$ HE aeroacoustic assessment of a turbofan is an essential step during the preliminary design of a modern aircraft engine. The evaluation of fan noise is notably important for take-off operation. The estimation of the flow field around the fan is a required base for the noise prediction. During the pre-design stage, the flow field evaluation is often conducted with so-called throughflow solvers [1-3]. Those solvers usually implement a streamline-curvature method and the spanwise distribution of flow quantities [4] is governed by the radial equilibrium of the flow. Losses, flow deviation and blockage are often resolved through more or less empirical correlations [5, 6]. Also secondary and endwall flow effects [7.-9] are considered by various codes. However, turbulence quantities are usually not predicted by these throughflow solvers during this early phase of jet engine design because they do not affect much the aerodynamic performance. But they have a direct impact on the broadband noise emission. Therefore, turbulence becomes important when computing the broadband component of the rotor-stator interaction noise source. There are models in the literature that provide semi-empirical correlations between wake parameters and turbulence quantities.

One of these models is used in an analytical approach based on the blade-response function by AMIET [10] to predict the aeroacoustic characteristics of a turbofan [11]. In this approach, the magnitudes of the acoustic dipoles distributed along the blade height affect the radiated pressure using a GreEn transfer function. The sound field is described with acoustic duct modes. The analytical approach is incorporated in a DLR (Deutsches Zentrum für Luft- und Raumfahrt, engl. German Aerospace Center) in-house tool called PropNoise. It supports several calculation modes depending on the flow quantities available prior to the acoustic estimation (see Fig. 11): The first mode is an integrated stand-alone method that calculates the flow characteristics based on a 1D meanline approach [11]. The meanline results are subsequently extrapolated in spanwise direction in order to obtain a radial distribution of the flow quantities along the fan height. Another mode relies on the external provision of flow data by a 2D throughflow solver which are, as mentioned before, already radially distributed [12]. The third supported mode allows to process directly the result from a 3D-RANS (Reynolds Averaged NAVIER-Stokes) simulation and to inform the acoustic models with this more refined information about the flow [13]. On the one hand a detailed representation of the geometry and boundary conditions are necessary but on the other hand it allows for the calculation of three-dimensional flow effects. Additionally, averaged turbulence quantities can be obtained from the RANS simulation. Hence, this mode does not rely on the aforementioned models for the estimation of turbulence and is therefore suitable for comparisons with the modeled wake turbulence. Other advantages of RANS simulations are the validations due to numerous applications and, compared to measurements for example, the easy and cheap access. The availability of robust experimental data is often restricted and very expensive.

We recently applied all three modes to a UHBR (Ultra High Bypass Ratio) fan designed by the DLR [14] and evaluated the noise source coming from the interaction of the rotor wakes with the downstream stator vanes [15]. The noise calculations for the approach condition showed a strong deviation for the broadband rotor-stator wake interaction noise, as shown in Fig. 22 The meanline (black) and throughflow (red) approach underestimated the noise level predicted by the RANS-informed (blue) approach by more than $10 \mathrm{~dB}$. It is suspected that the so far implemented semi-empirical model for the calculation of rotor turbulence is responsible for this offset.

Figure 3 shows the flow-specific quantities describing the loss and turbulence generated by the rotor. It becomes apparent that the simpler 1D- and 2D-based modes underestimate the turbulence statistics (middle and right figure) when considering the 3D mode as the reference. Later in this paper, we want to verify this assumption with measurement data. The increase of turbulence in the hub and tip regions provided by the 3D RANS simulation is stronger and also the level 


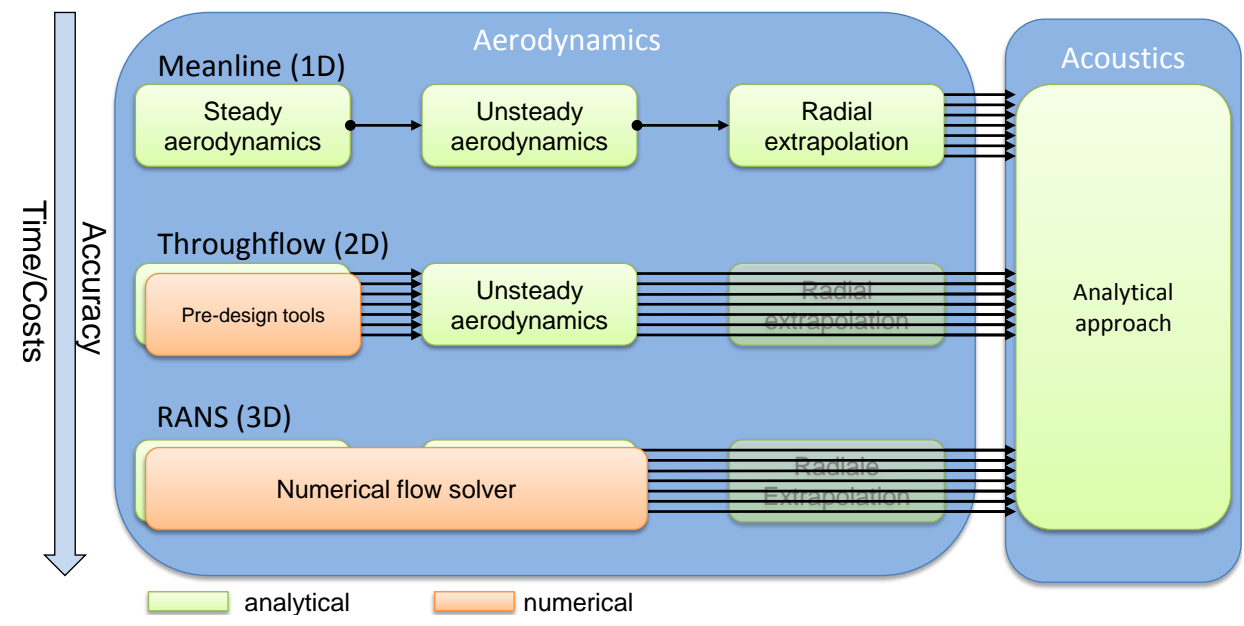

Fig. 1 Overview of the three hybrid modes for calculating fan acoustics. The modes differ mainly for the calculation of the steady and unsteady flow field.

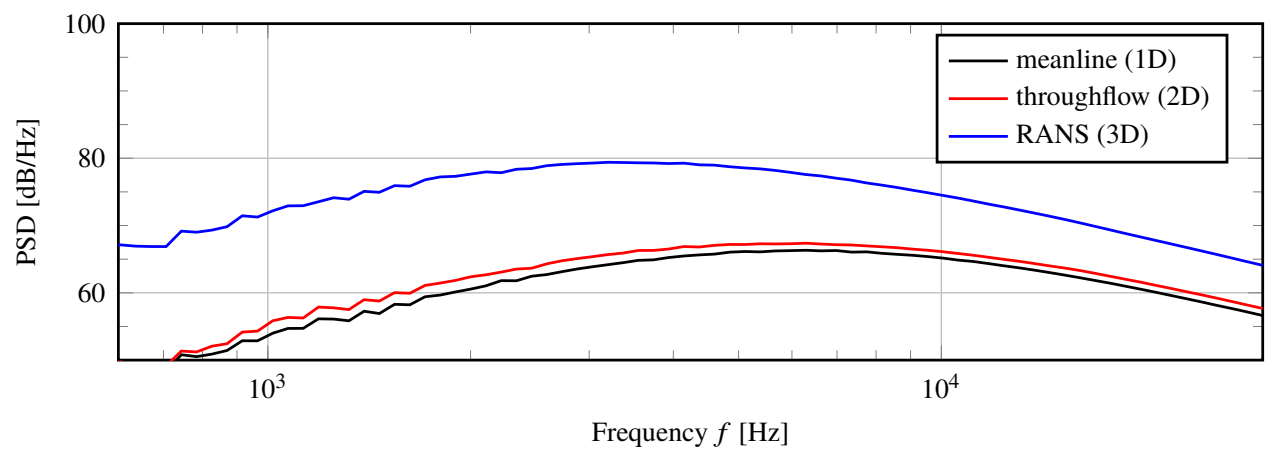

Fig. 2 Broadband power spectral density (PSD) for wake interaction noise source of the DLR-UHBR fan for approach operation.

of turbulent intensity and length scale in the mid-span region is higher. In contrast, we notice a good estimation of the radial average value for the total-pressure loss coefficient of the rotor (left figure) by the 1D and 2D modes. This result suggests that the underestimation in the noise levels is attributable to the inaccurate modeling of the turbulent quantities from a given loss coefficient, rather than a wrong prediction of the loss coefficient itself.

Thus, we suppose that the formulation for the turbulence estimation and the according constant factors need to be revised. In addition to that, other aspects related to the flow in the endwall regions may also have a contribution to the overall broadband interaction noise. In the end, we want to tackle the following three questions in this paper:

1) Can we confirm the assumption of the models, which correlate rotor losses and wake turbulence (section V.B. ?

2) How much gain in accuracy can we expect from an improvement of the turbulence modeling (section V.C)?

3) How strong is the influence of endwall flow on the emitted noise, compared to the contribution from the flow away from the endwalls (section V.D? 

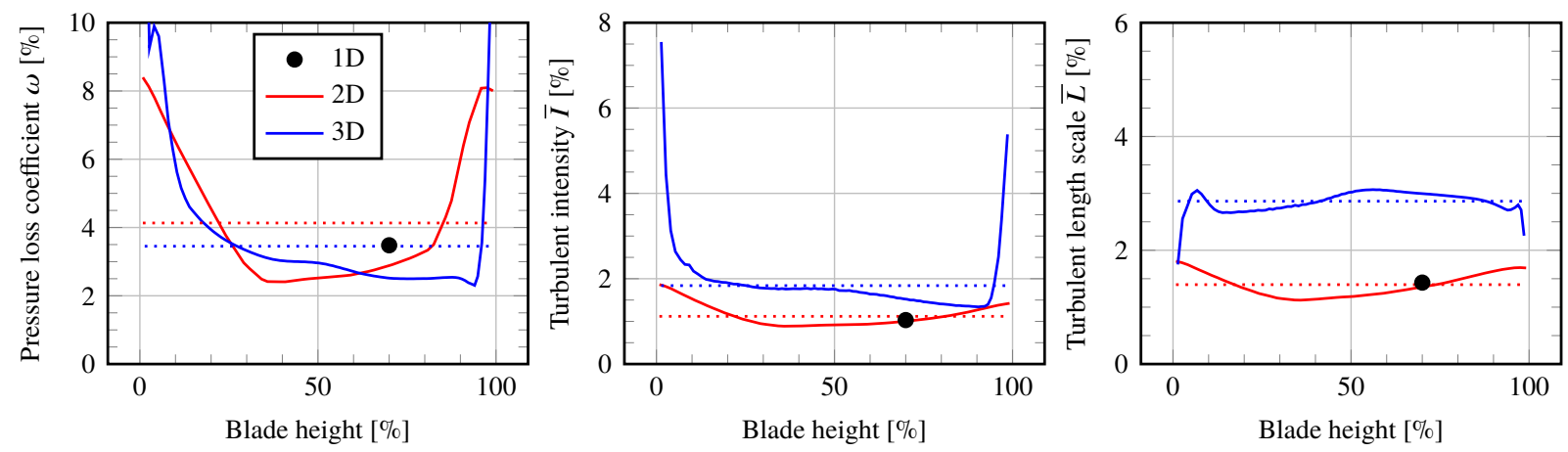

Fig. 3 Radial distribution (solid) and average (dotted) of the rotor pressure loss coefficient $\omega$ and the circumferentially averaged turbulence statistics, turbulent intensity $\bar{I}$ and the normalized turbulent length scale $\bar{L}$, in the rotor wakes of the DLR-UHBR fan for approach operation.

\section{Theory}

The turbulent velocity fluctuations in the rotor wakes are the source for the broadband component of the rotor-stator interaction noise. When making the assumption of isotropic turbulence and small correlation lengths, it is possible to reconstruct the turbulent velocity spectrum from turbulence statistics like turbulent kinetic energy (TKE) $k$ and turbulent length scale (TLS) $\Lambda$. To put it in simple terms, the TKE influences the magnitude and the TLS influences the frequency range of the von KARMAN spectrum of the velocity fluctuations. The currently applied approach [11] for the determination of the circumferentially averaged TKE $\bar{k}$ and TLS $\bar{\Lambda}$ assumes a proportional correlation to the square of the wake velocity deficit $u$ and the wake width $w$ as well as the streamtube height $h_{l}$ [16, 17]:

$$
\begin{aligned}
& \bar{k}=\frac{3}{2} \sum_{h=-\infty}^{+\infty}\left(K_{U} \cdot u(h)\right)^{2} \\
& \bar{\Lambda}=K_{L} \cdot w \cdot h_{l}
\end{aligned}
$$

Hence, it is assumed that the circumferential profile of turbulence is directly related to the profile of the mean wake. The model correctly replicates the increase of turbulence intensity and length scale if the blade loading and losses increase [16, 18]. The empirical constants $K_{U}$ and $K_{L}$ need to be calibrated and are subject of some studies. In the literature they vary for $K_{U}=0.2-0.4$ and $K_{L}=0.2-0.6$. So far, we adopted a value of $K_{U}=0.3$ from [17] and a value of $K_{L}=0.2$ from [19] for our studies. This choice is examined carefully in section V.C.

The train of mean wakes behind a blade row is assumed to consist of identical, symmetrical and Gauss-shaped velocity distributions in circumferential direction. The spectral content of the streamwise velocity perturbation $u(h)$ is a function of the wake harmonic $h$ and depends on the circumferentially averaged velocity $\bar{W}$ and the wake shape parameters:

$$
u(h)=\bar{W} \cdot A \cdot e^{-\pi \cdot w^{2} \cdot h^{2}}
$$

The wake shape is characterized by the three non-dimensional parameters area $A$, depth $d$ and width $w$.

$$
\begin{aligned}
A & \equiv \int_{0}^{s} \frac{u(y)}{\bar{W}} \frac{\mathrm{d} y}{s} \\
d & \equiv \frac{u_{\max }}{W_{\max }} \\
w & \equiv \frac{A}{d}
\end{aligned}
$$

with the spatial velocity perturbation $u(y)$, the blade pitch spacing $s$, the peak perturbation velocity $u_{\max }$ and the undisturbed flow velocity $W_{\max }$ behind the rotor cascade. Since wakes can basically be regarded as the propagated boundary layers generated on a blade surface, the wake parameters can be related to the boundary-layer thickness. This 
relation is depicted in Fig. 4. We make the assumption that the displacement thickness at the trailing edge of the blade remains constant when axially propagating in the wakes. When the wake continues to propagate between the rotor and the following cascade, it starts to decay and merge with the adjacent wakes. The calculation of the streamwise development of the non-dimensional mean wake quantities is described in [11].

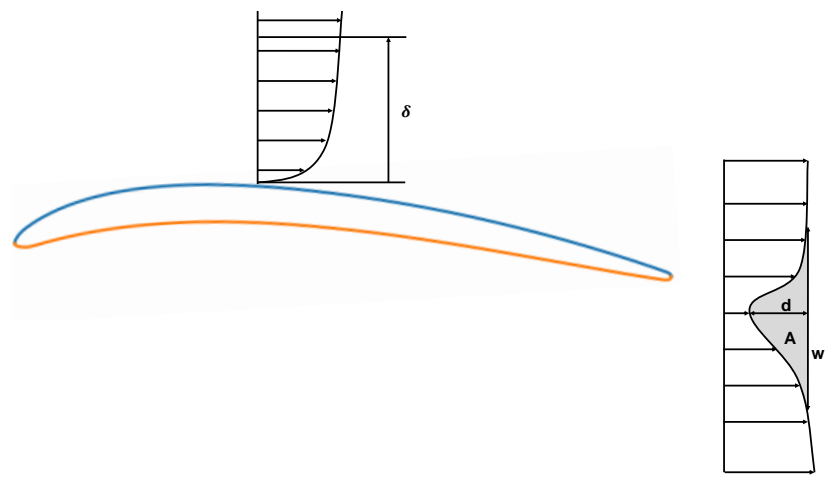

Fig. 4 Parameters of the boundary layer and the wake generated by a turbofan airfoil.

A mathematical connection between the boundary layer on the blade surface and the wake parameters following the blade can be established. The following expressions are derived from their definitions and the Gaussian-shape of the wake:

$$
\begin{aligned}
& A=\frac{\delta_{1}}{h_{l}-\delta_{1}} \\
& d=\sqrt{2}(1+A)\left(1-H_{12}^{-1}\right)
\end{aligned}
$$

Derived from [20], the displacement thickness $\delta_{1}$ can be approached with the viscous drag coefficient of the blade $c_{D \text {,visc }}$ and the momentum thickness $\delta_{2}$ by the shape factor $H_{12}=\delta_{1} / \delta_{2}$, which depends on the pressure gradient and is calculated with the diffusion factor.

$$
\begin{aligned}
\delta_{2} & =\frac{1}{4} c_{D, \mathrm{visc}} \cdot c \cdot \frac{3 H-1}{H} \quad \text { with } \quad H=1.08 \\
\delta_{1} & =\delta_{2} \cdot H_{12}
\end{aligned}
$$

Since the total-pressure loss coefficient $\omega=\Delta p_{t} /\left(p_{t, \text { in }}-p_{\text {in }}\right)$ is the rather common quantity for cascades, we use the solidity $\sigma$ and a mean value of the inflow and outflow angle $\beta_{m}$ to link the drag to the loss coefficient.

$$
c_{D}=\omega \frac{\cos \beta_{m}}{\sigma}
$$

The viscous loss is that part of the overall losses which is caused by the boundary layers on the blade profiles. The viscous profile losses or blade drag respectively can be provided by the aforementioned pre-design tools but not by a RANS simulation. This challenge is described in the following section.

\section{Methodology}

In this section, the line of action for the investigation of the presented wake turbulence model is discussed. First, a brief description of each considered fan stage is given. And second, the data acquisition of the flow information from the throughflow solver as well as the CFD-RANS solver is described. 


\section{A. Investigated fans}

In order to investigate the turbulence characteristics in rotor wakes, we selected four different turbofans: DLR UHBR, ACAT1 (AneCom AeroTest Rotor 1), NASA (National Aeronautics and Space Administration) SDT (Source Diagnostic Test) and ASPIRE (Aerodynamic and acouStic for high-by-Pass ratIo tuRbofan intEgration). The selected test cases for this study are representative for fan stages of modern aero-engines. A summary of the parameters for each fan stage is given in Table 1 .

Table 1 Geometric and aerodynamic parameters of the four considered turbofans.

\begin{tabular}{|l|l|l|l|l|}
\hline & DLR UHBR & ACAT1 & NASA SDT & ASPIRE \\
\hline Geometry & & & & \\
\hline Rotor diameter $d$ & $0.8 \mathrm{~m}$ & $0.85 \mathrm{~m}$ & $0.55 \mathrm{~m}$ & $2.28 \mathrm{~m}$ \\
\hline Rotor blades $B$ & 22 & 20 & 22 & 16 \\
\hline Stator vanes $V$ & 38 & 44 & 54 & 36 \\
\hline Aerodynamic design point & & & & \\
\hline Relative tip Mach number $M_{\text {tip,rel }}$ & 1.14 & 1.17 & 1.27 & 1.04 \\
\hline Axial Mach number $M_{x}$ & 0.63 & 0.65 & 0.6 & 0.59 \\
\hline Fan pressure ratio $\Pi$ & 1.4 & 1.42 & 1.47 & 1.31 \\
\hline Approx. bypass ratio $\mu$ & 12 & 8 & 9 & 16 \\
\hline
\end{tabular}

The DLR UHBR fan was designed by the Institute of Propulsion Technology at the DLR [14, 21]. It is a scaled 1:3 model compared to the fan stage of a real aircraft engine. The fan is representative of a modern engine design with a high bypass ratio. The stator vane count has been selected in order to make the first harmonic of the blade passing frequency cut-off during approach. A mounted version of the fan has been operated and measured on a test facility at the DLR in Cologne [22, 23].

The transonic ACAT1 fan is similar in terms of size and pressure ratio to the DLR UHBR fan being a 1:3 model, too. It was experimentally investigated in the Universal Fan Facility (UFFA). An extensive database was created in the framework of the EU (European Union) project TurboNoiseBB with the aim to expedite research on the field of broadband noise. The measurements comprise airflow data by means of hot-wire anemometry and acoustic data by means of pressure sensors. The mounted fan stage has a bypass and a core stream with a design mass flow ratio of about eight. Both the OGVs (Outlet Guide Vanes) in the bypass duct and the stator vanes in the core duct have the same number of blades. Several versions of fan geometry and working lines were investigated: The distance between rotor and OGV was varied with a short gap (SG) and a long gap (LG) version. Additionally, a low noise (LN) and sea-level-static (SLS) working line was explored. In this paper, we examine the SG variant and both working lines. Numerical RANS-simulations coupled with our analytical method have been conducted in the past [24, 25].

The NASA SDT fan was designed by the General Electric Corporation with partial funding from NASA [26]. It is also a research fan model with the scale of 1:5 in relation to a modern turbofan with a high bypass ratio. The focus is on low noise design in order to give an understanding of the noise generation mechanisms. Extensive acoustic measurements were conducted in the Low Speed Wind Tunnel (LSWT) at the NASA Glenn Research Center [27, 28]. Moreover, aerodynamic measurements of the rotor wake characteristics using laser DopPLER velocimetry were conducted [29].

The ASPIRE full-scale fan stage has a bypass and core section, too, and was again designed by the Institute of Propulsion Technology at the DLR [30] within the framework of the EU project ASPIRE and according to specifications provided by Airbus. The goal was to create a fan of a next-generation engine design. Hence, the bypass ratio at the aerodynamic design point of 16 is much higher than that of recent civil aero-engines. Simultaneously, the pressure ratio is comparatively low. While the number of stator vanes were fixed, the number of rotor blades were aerodynamically and structurally optimized in order to make the blade passing frequency cut-off for three operating points (approach, cutback and sideline). Numerical simulations have already been conducted for this fan concept [31].

The selected turbofans cover a wide range concerning fan pressure ratio (ranging from 1.3 to 1.5 ) and bypass ratio (ranging from 8 to 16). There is one full-scale fan (ASPIRE) and two set-ups having a physical core flow (ACAT and ASPIRE). The idea is to analyze the extensive database provided by measurements as well as numerical simulations from those fan stages and examine the turbulence intensity, integral length scale in the rotor wakes and pressure losses 
induced by the fan rotor. Several operating points will be considered, in order to cover a wide range of Mach numbers. The design point with very low incidence serves as a reference. Take-off operating points have a high loading and low incidence which results in a moderate wake turbulence whereas an approach operating point for moderate-to-low fan pressure ratios should induce increased incidence, maybe even flow separation, which in turn increases the wake turbulence. If variable-geometry devices are used, as it is the case for the ASPIRE fan which incorporates a Variable Area Nozzle (VAN), the wake turbulence may be low even for approach conditions. In this paper, the take-off operating points, sideline and cutback, and the approach operating point are mostly investigated since these are the most important points for aircraft noise certification.

\section{B. Data acquisition of aerodynamic losses and turbulence}

As already mentioned in the introduction section, a throughflow solver can provide the pressure loss generated by a blade row. A RANS simulation additionally provides turbulent quantities like TKE and TLS. The data acquisition of these quantities are briefly described in this section.

The throughflow calculations are conducted with the DLR streamline curvature solver ACDC (Advanced Compressor Design Code) [32]. The aerodynamic loss is obtained from empirical correlations which are calibrated with an ambitious method described in [6]. This process also allows to distinguish loss components like viscous profile loss or shock-induced loss. The discretization for throughflow calculations is usually rather coarse. The number of radially distributed streamlines counts about 20. An interface extracts the data on axial stations before and behind the blade rows. Subsequently, it converts and interpolates the data to a format that can be evaluated by PropNoise.

The 3D-RANS simulations are conducted with the DLR CFD (Computational Fluid Dynamics) solver TRACE [33]. The steady-state simulations all use a Menter SST (Shear Stress Transport) $k-\omega$ turbulence model. Recommended turbulence model extensions supported by TRACE (concerning rotation, transition and the stagnation point) are applied based on a best-practice study detailed in [34] for RANS-informed prediction of fan broadband interaction noise. The fan domain is discretized with a multi-block grid and the number of cells varies between 4 and 9 million cells depending on the fan. Special care has been taken for the mesh in the boundary-layer and tip region as well as the space between rotor and stator especially if a splitter is present. The domain is split up in a moving rotor block and a steady stator block. These blocks are divided by a mixing plane which circumferentially averages the flow information. Another interface extracts the data from the RANS solution and again converts it to a format that can be evaluated by PropNoise. In order to have non-averaged information about the wakes and turbulence at the stator available, the interface extrapolates the data from the mixing plane to the stator [13].

In the following sections, the turbulence quantities like kinetic energy and length scale are always obtained at the stator leading edge. The quantities can be compared despite the wakes' decay during their propagation between rotor trailing edge and stator leading edge since the relative distance is very similar for all fan stages. It usually corresponds to the chord length of the rotor except for the SDT case which is about 1.7 times the chord length. But the results do not show particularly low turbulence for the NASA SDT fan at the stator leading edge.

Unfortunately, we were able to apply the throughflow calculations only to the DLR UHBR fan stage for the moment. Thus, we compared the 1D meanline with the 3D RANS-based results in section V.A in order to investigate on the deficits of the turbulence model. This is a valid practice since the turbulence model is applied to each streamline separately for the 2D throughflow mode, as it can be observed in Fig. 1. Only the calculation of the steady aerodynamics differs for the 1D and 2D modes, which mainly concerns the comparison of the aerodynamic loss in this case. For section V.B we substituted the input for the 2D mode with RANS data, which is called "synthesized input" consecutively. This works very well since all the necessary input is available from the RANS interface, too. On the one hand, this is beneficial because we maintain a neat comparison due to the same source for the input. On the other hand, we actually need the viscous profile loss component induced by the boundary layers for the turbulence model as described in Eq. 9 But from a RANS calculation we get the overall loss without the separation between components like the boundary-layerand shock-related contribution. Here we make the assumption that especially in the mid-span region we do not expect a prominent difference between overall loss and viscous loss. [35] In regions (especially at the rotor tip) where the inflow Mach number exceeds a certain value we try to reduce the influence by shock loss as we clip the overall loss and remove the strong increase of loss in the respective region. This is visualized later in the relevant section.

An overview of all cases for data acquisition is given in Table 2. These cases are all available for comparisons in the following sections. For clarity an acronym is given for each pair that consists of a fan and an operating point combination. 
Table 2 Overview of the investigated cases. The acronym is used in the following figures when comparing all cases. The studies have been conducted with all modes but the input for most 2D-based modes were obtained from CFD solver instead of throughflow solver (syn. = synthesized input).

\begin{tabular}{|l|l|l|l|l|l|}
\hline Fan & Operating point & Acronym & 1D & 2D & 3D \\
\hline \multirow{3}{*}{ DLR UHBR } & Approach & UHBR-AP & yes & yes & yes \\
& Bucket cruise & UHBR-BC & yes & yes & yes \\
& Take-off & UHBR-TO & yes & yes & yes \\
\hline \multirow{3}{*}{ ACAT1 (SG, LN) } & Approach & ACAT-SG-LN-AP & yes & syn. & yes \\
& Cutback & ACAT-SG-LN-CB & yes & syn. & yes \\
& Sideline & ACAT-SG-LN-SL & yes & syn. & yes \\
\hline \multirow{3}{*}{ ACAT1 (SG, SLS) } & Approach & ACAT-SG-SLS-AP & yes & syn. & yes \\
& Cutback & ACAT-SG-SLS-CB & yes & syn. & yes \\
& Sideline & ACAT-SG-SLS-SL & yes & syn. & yes \\
\hline \multirow{2}{*}{ NASA SDT } & Approach & SDT-AP & yes & syn. & yes \\
& Sideline & SDT-SL & yes & syn. & yes \\
\hline \multirow{3}{*}{ ASPIRE } & Approach & ASPIRE-AP & yes & syn. & yes \\
& Cutback & ASPIRE-CB & yes & syn. & yes \\
& Sideline & ASPIRE-SL & yes & syn. & yes \\
\hline
\end{tabular}

\section{Analysis and discussion}

The model is implemented in the fan acoustics prediction code as described in section [III Starting with the loss in Eq. 11 it is possible to estimate the turbulence quantities in Eqs. 1 and 2. In order to obtain a better understanding of the modeled turbulence estimation and to figure out the cause of the mismatch in noise prediction shown in Fig. 2, we started to apply the methods to the fan stages and operating points listed in Table 2 . We compared the modeled turbulence characteristics with the characteristics obtained from the RANS simulation. The turbulent parameters TKE and TLS are translated to the non-dimensional parameters turbulent intensity $I$ and length scale $L$ in relation to rotor-blade chord length $c$ :

$$
\begin{aligned}
& I=\frac{\sqrt{2 / 3 k}}{\bar{W}} \\
& L=\frac{\Lambda}{c}
\end{aligned}
$$

Since the viscous pressure loss coefficient $\omega_{\text {visc }}$ is the key quantity for estimating the TKE and TLS, the three quantities $I, L$ and $\omega$ are plotted and examined hereinafter. The PSD (Power Spectral Density) spectrum and integrated OAPWL (OverAll PoWer Level) as a scalar value are used to survey the influence on the interaction broadband noise.

\section{A. Underestimated wake turbulence}

In addition to the UHBR test case discussed in the introduction section, more fans were investigated regarding the turbulence modeling. Another example which underlines the underestimation of wake turbulence is shown in Fig.5. This represents the ACAT fan (SG, SLS) during approach operation.

Since the analytical fan-acoustics evaluation tool considers exclusively the interaction noise between the rotor and the OGV in the bypass section, the RANS interface extracts the data only for the streamlines that enter the bypass. This is why the the plots start at about $20 \%$ of the duct height in relation to the rotor radius. As for the UHBR case, the pressure loss is very well predicted by the 1D meanline approach both on the meanline station and compared to the radially averaged value of the RANS calculation (left). But the circumferentially averaged, non-dimensional wake turbulence parameters are again underestimated by a factor of 0.5 (middle and right).

The modeled wake turbulence results in an underestimation of noise for about $10 \mathrm{~dB}$ as it can be seen in the 

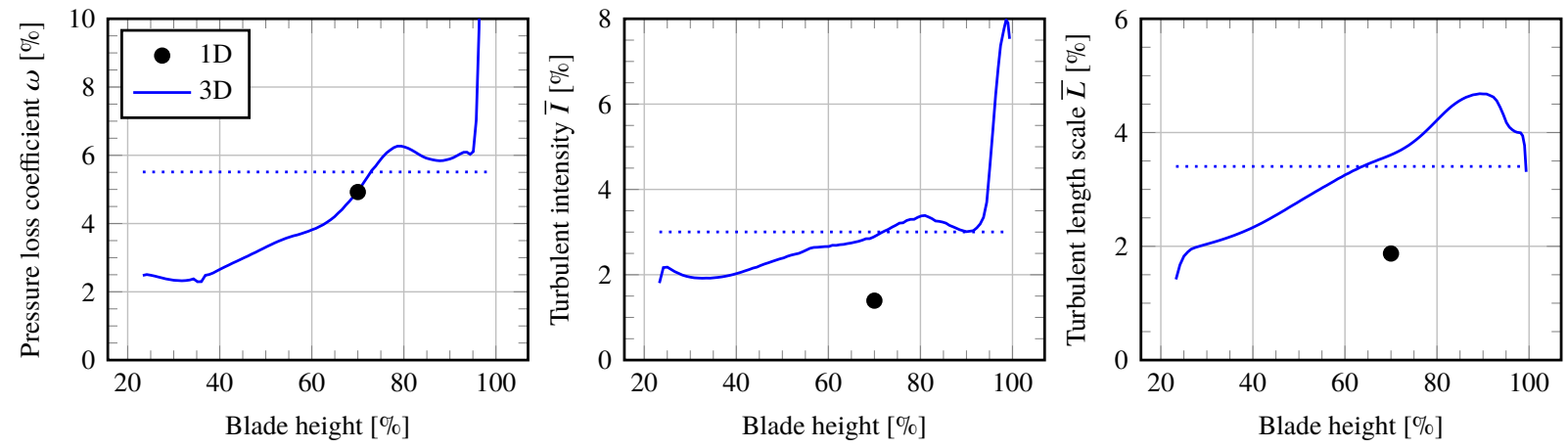

Fig. 5 Radial distribution (solid) and average (dotted) of the rotor pressure loss coefficient $\omega$ and the circumferentially averaged turbulence statistics, turbulent intensity $\bar{I}$ and the normalized turbulent length scale $\bar{L}$, in the rotor wakes of the ACAT fan for approach operation (short-gap version, sea-level static working line).

spectrum in Fig. 6 A comparison with downstream microphone measurements indicates the good match with the 3D RANS-informed mode and supports the assumption to use this mode as a reference.

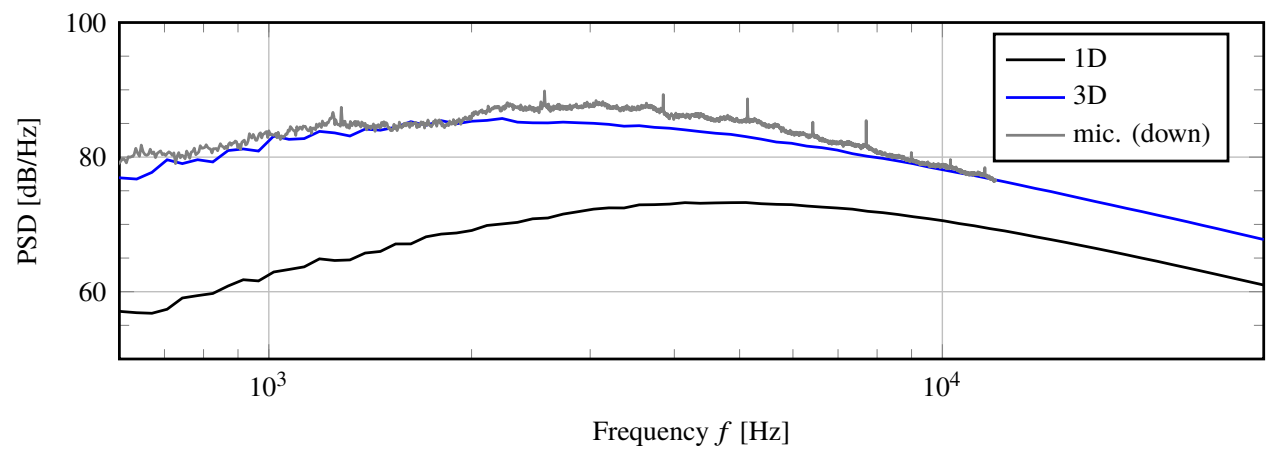

Fig. 6 Broadband power spectral density (PSD) for wake interaction noise source of the ACAT fan for approach operation (short-gap version, sea-level static working line) compared to downstream microphone measurements (mic.).

Considering the pressure loss coefficient as the input and the OAPWL value as the result, a comparison of these values for all investigated cases should give an indication on the capability of the presented model to predict the wake turbulence. An overview of the ratio $f_{\omega}$ between the calculated loss of the 1D mode $\omega_{1}$ and the radially averaged value of the 3D mode $\omega_{3}$ is given in Fig.7 7 plotted in black color. The overall power-level difference $f_{P}=\Delta \mathrm{OAPWL}=\mathrm{OAPWL}_{1}-\mathrm{OAPWL}_{3}$ is plotted in blue color. A perfect match of the loss prediction or the OAPWL would result in a value of 1 (left axis) or a value of $0 \mathrm{~dB}$ (right axis) respectively.

A tendency that the noise is underestimated with the 1D mode for all cases is very obvious. Especially the approach operating points diverge from the RANS-based prediction for all fan stages. This might be caused by the secondary flow phenomena occurring during these low-speed operating points which are not covered by the model and which lead to a higher level of turbulence in the RANS simulations. The model underpredicts the overall noise levels with an average of $\overline{f_{P}}=-6.32 \mathrm{~dB}$ (standard deviation $\sigma_{P}=2.67 \mathrm{~dB}$ ). Interestingly, we can observe that the prediction of loss is quite well for some cases and by trend rather overestimated with an average of $\overline{f_{\omega}}=1.18$ (standard deviation $\sigma_{\omega}=0.27$ ). This confirms the hypothesis that the link between input and output (the wake turbulence model) must be a source of error and not the input itself (the loss coefficient).

\section{B. Correlation of rotor losses and wake turbulence}

In order to validate the hypothesis that we can effectively derive the wake turbulence from the viscous pressure loss, we need to check if the flow exhibits some kind of correlation with a single parameter. If this state is proven, the mean 


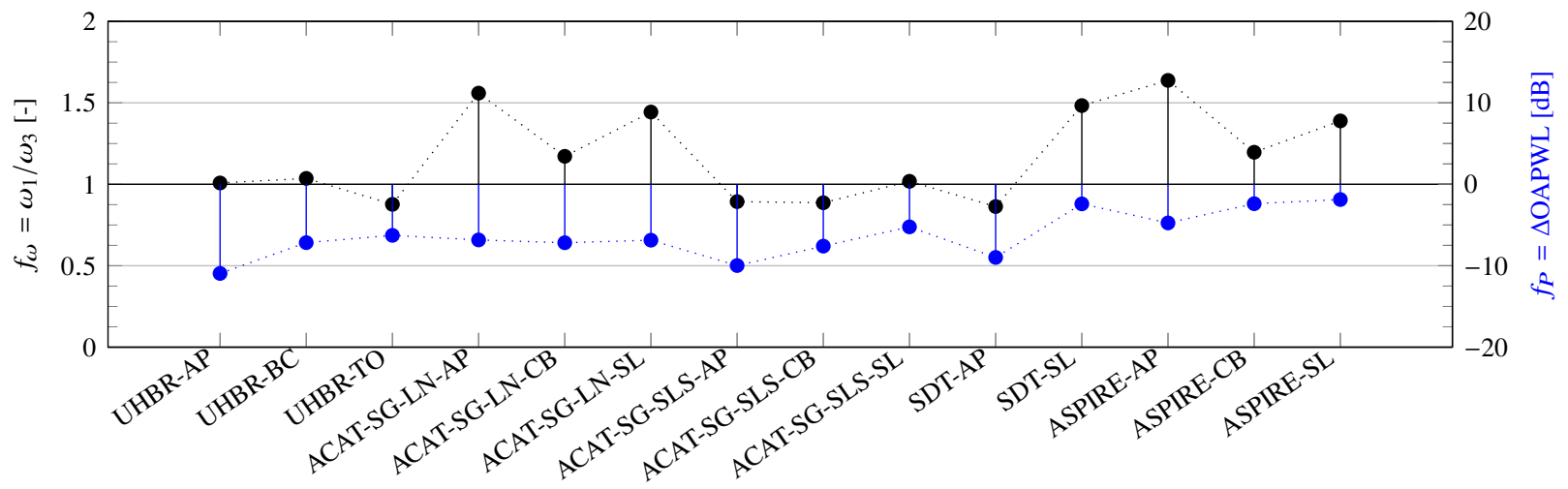

Fig. 7 Ratio of the pressure loss coefficient $\omega$ (black) and difference between the OAPWL values (blue) based on the 1D and 3D approach listed for all considered points.

and turbulent wake might be determined at the OGV from the pressure loss across the rotor. A simple ratio between the circumferentially and radially averaged turbulent wake quantities $I_{3}$ and $L_{3}$ and the radially averaged total-pressure loss coefficient of the rotor $\omega_{3}$, all obtained from the RANS simulations, is constituted and compared for all cases. If these ratios $f_{I}=I_{3} / \omega_{3}$ and $f_{L}=L_{3} / \omega_{3}$ remain constant for the various fans and even operating points, it might be legitimate to assume a proportional relation between rotor losses and wake turbulence. A higher variance of the ratios $f_{I}$ and $f_{L}$ signify that the relation between rotor loss and wake turbulence is not directly proportional but rather more complex because of more complex flow phenomena. The ratios are depicted in Fig. 8 .
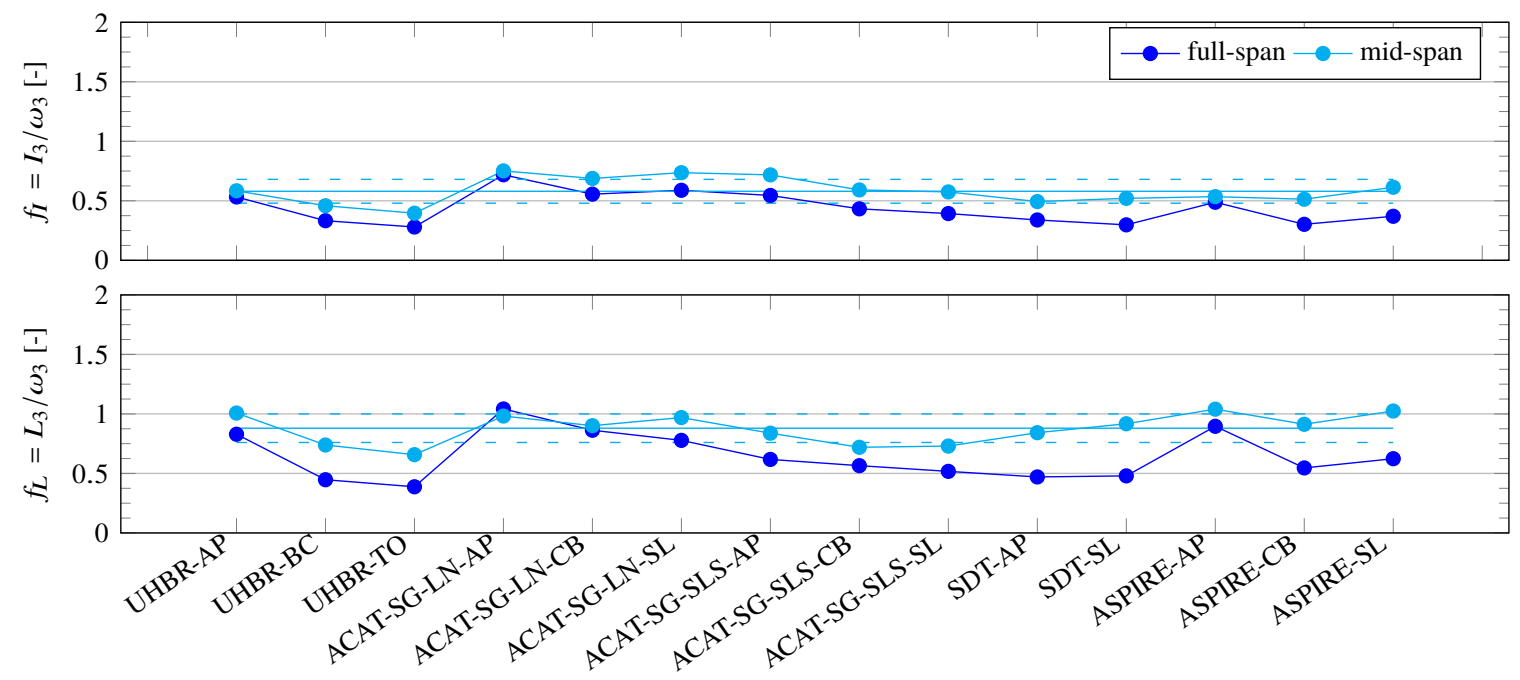

Fig. 8 Ratio of the turbulence quantities to the pressure loss coefficient $\omega$ based on the 3D approach listed for all considered points. The cyan color indicates the values obtained from the mid-span region only, thus omitting the flow effects in the hub and tip region. The arithmetic mean (solid) and the standard deviation (dashed) are plotted for the mid-span cases.

As mentioned earlier in section IV.B the viscous pressure loss is not available from the RANS solution. But the overall profile loss in the unaffected mid-span region is similar to the viscous loss if shock losses are negligible. In fact, we can observe in the diagram that the values for the mid-span vary less than the ratios based on the full-span. A solid line represents the arithmetic mean for all mid-span values and the dashed lines show the standard deviation. While the exact mean value is not primarily important in this section, the standard deviation illustrates the grade of variance throughout the several RANS simulations. The values of arithmetic mean and standard deviation are also listed in Table 3 
Table 3 Arithmetic mean $\bar{f}$ and standard deviation $\sigma$ of the ratios shown in Fig. 8 . The statistics distinguish between the full-span, mid-span, hub (not shown in the figure) and tip (not shown in the figure) region.

\begin{tabular}{|l|l|l|l|l|}
\hline & full-span & mid-span & hub region & tip region \\
\hline Turbulent intensity $f_{I}=I_{3} / \omega_{3}$ & & & & \\
\hline$\overline{f_{I}}$ & 0.44 & 0.58 & 0.91 & 0.34 \\
\hline$\sigma_{I}$ & 0.13 & 0.1 & 0.63 & 0.14 \\
\hline Turbulent length scale $f_{L}=L_{3} / \omega_{3}$ & & & & \\
\hline$\overline{f_{L}}$ & 0.65 & 0.88 & 0.57 & 0.56 \\
\hline$\sigma_{L}$ & 0.19 & 0.12 & 0.12 & 0.26 \\
\hline
\end{tabular}

The standard deviation is quite low with values of $\sigma_{I}=0.1$ and $\sigma_{L}=0.12$ for mid-span. In addition to the full-span and mid-span regions, the ratios and their respective means and standard deviations are also calculated for the isolated hub and tip region (apart from the mid-span region). As expected, the variance is much higher in the isolated hub and tip regions due to more complex flow phenomena. But the grades of variance seem to contradict since the standard deviation is very high for the turbulent intensity ratio in hub region and turbulent length scale ratio in the tip region.

In general, we can state that Fig. 8 and Table 3 show almost constant ratios between turbulence and loss, especially for mid-span area. Hence, a proportional correlation of those values is a valid approach. In sectionV.D we will highlight the contribution of the turbulence outside the mid-span region to the noise estimation.

\section{Adjustment of empirical constants}

Because the correlation described in section III seems to be a valid approach as worked out in the preceding section, the next question is if an adjusted value of the empirical constants $K_{U}$ and $K_{L}$ from Eqs. 1 and 2 can lead to better fan noise prediction. The constants are adjusted manually and kept constant for all cases. That is, we tried a range of values and observed the effect on the noise prediction. A value pair is identified which works best for most of the cases.

It was already mentioned in section IV.B that the calculations with the throughflow solver were not carried out on all investigated fans. We still wanted to use the 2D mode in which the wake turbulence model is applied to each streamline separately. Thus, in contrast to the meanline calculations in section V.A radial distributions of the turbulence quantities become available. The input is synthesized from data of the RANS simulations and the viscous loss coefficient is replaced with an adapted overall loss coefficient. In order to avoid the influence of shock losses, the loss coefficient is clipped when the inflow Mach number of the rotor in relative frame of reference exceeds a value of 0.85 . This procedure can be observed on the left of Fig. 9 for the ACAT fan (SG, SLS) during cutback operation (take-off). The graphs basically overlap for the pressure loss coefficient used for 2D and 3D mode. But when the loss starts to increase in the tip region due to shocks, the loss for the 2D mode is replaced with a linear extrapolation.
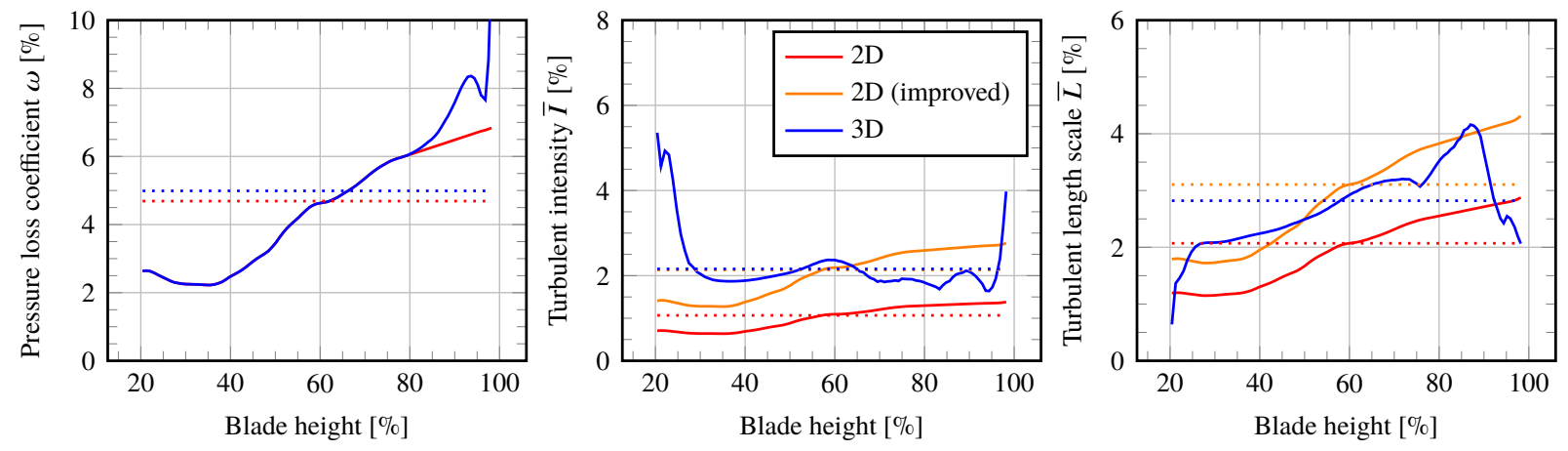

Fig. 9 Radial distribution (solid) and average (dotted) of the rotor pressure loss coefficient $\omega$ and the circumferentially averaged turbulence statistics, turbulent intensity $\bar{I}$ and the normalized turbulent length scale $\bar{L}$, in the rotor wakes of the ACAT fan for cutback operation (short-gap version, sea-level static working line). The orange color indicates the calculated turbulence quantities with adjusted empirical constants. 


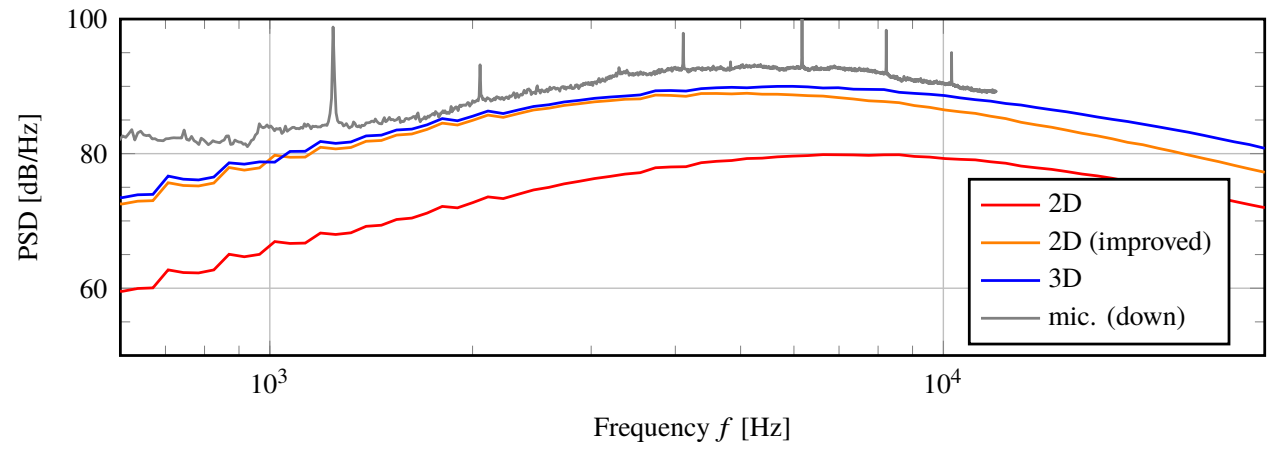

Fig. 10 Broadband power spectral density (PSD) for wake interaction noise source of the ACAT fan for cutback operation (short-gap version, sea-level static working line) compared to downstream microphone measurements (mic.). The orange color indicates the broadband spectrum with adjusted empirical constants. 
The red graphs in the middle and on the right again show underestimated turbulent intensity and turbulent length scale when calculated with the model compared to the blue graphs obtained from 3D RANS simulation. Since the quantities for the 2D mode are modeled from the loss, the radial evolution is very similar and does not resemble the trends from the RANS simulation. But the radially averaged values are again underestimated by a factor of 0.5 . When increasing the values for the empirical constants from $K_{U}=0.3$ to 0.6 and from $K_{L}=0.2$ to 0.3 , the graphs and their averages tend to fit much better with the simulated references. The turbulent length scale is a bit overestimated but the turbulent intensity matches very well. The choice of the new constants is in agreement with [17] for $K_{U}$ and [16] for $K_{L}$. Consequently, a much better broadband noise prediction can be achieved as shown in Fig. 10.

The PSD spectrum shows a significantly improved agreement between the 3D RANS-informed mode and the improved 2D-informed mode especially in the low frequency range. The spectra diverge in the high frequency range because the maximum of the 2D-based spectrum is shifted to lower frequencies due to the overestimated turbulent length scale. The microphone measurements seem to coincide with both calculated spectra as we similarly confirmed for the approach point in Fig. 6 .

The relation between the $2 \mathrm{D}$ and $3 \mathrm{D}$ modes is computed with the ratio for the radially averaged turbulence (dotted lines in Fig. 9] and the OAPWL difference. This is supposed to help assessing an improvement in the statistical trend of the adjusted empirical constants for all test cases. The ratios $f_{I}=I_{2} / I_{3}$ and $f_{L}=L_{2} / L_{3}$ as well as the difference $f_{P}=\Delta \mathrm{OAPWL}=\mathrm{OAPWL}_{2}-\mathrm{OAPWL}_{3}$ are depicted in Fig. 11 . Again, a value of 1 for the ratios and a value of $0 \mathrm{~dB}$ for the difference indicate a perfect match between model and reference. All cases are calculated with the same adjusted constants of $K_{U}=0.6$ and $K_{L}=0.3$. In general, results fit better for most of the cases as shown in the figure. All dots are basically shifted upwards to the value of 1 or $0 \mathrm{~dB}$. The average is plotted as a solid line.
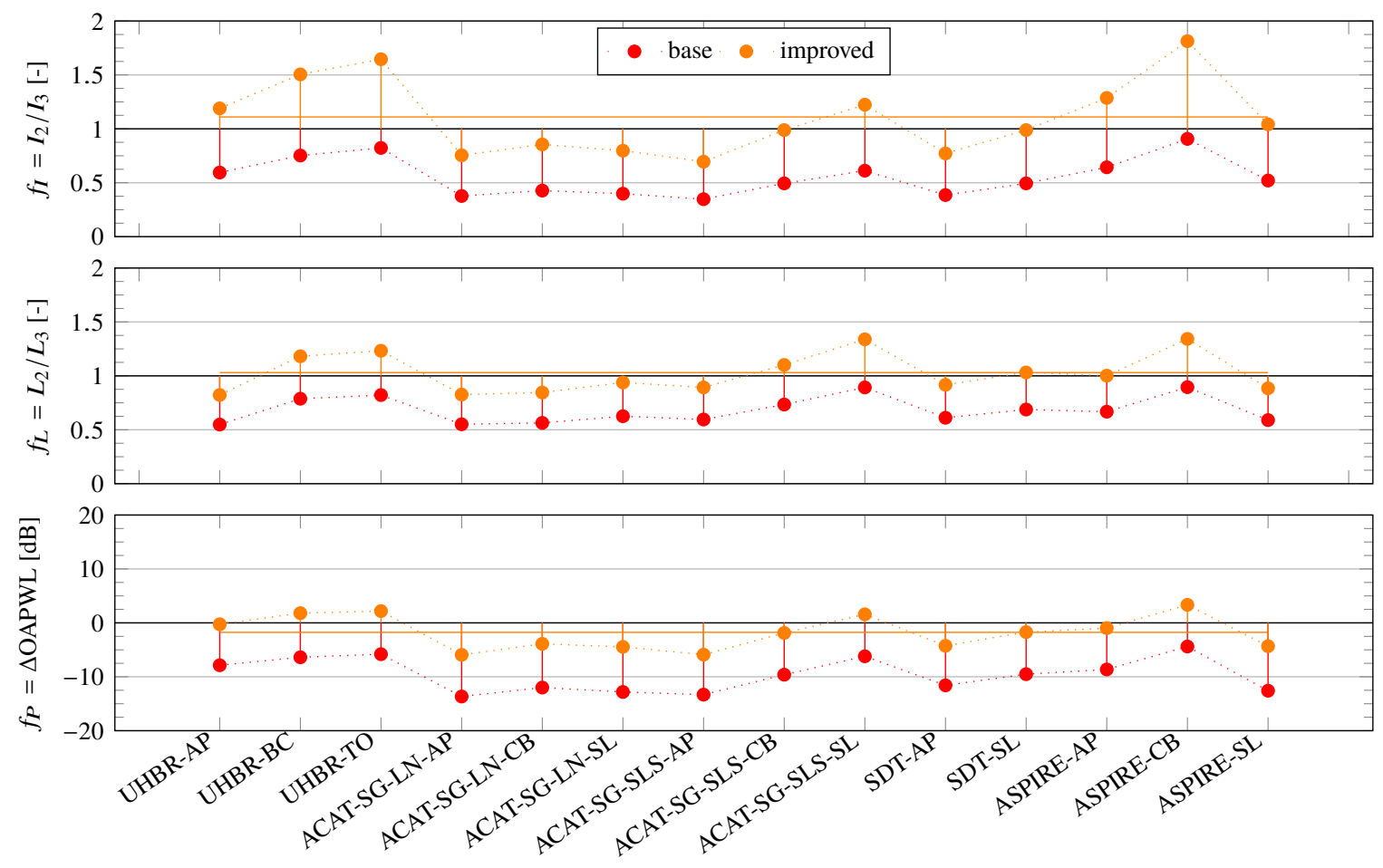

Fig. 11 Ratio of the turbulence quantities and difference between the OAPWL values based on the 2D and 3D approach listed for all considered points. The orange color indicates the calculated turbulence quantities and OAPWL values with adjusted empirical constants. The arithmetic mean (solid) is plotted for the improved cases.

A comparison of the arithmetic mean and the standard deviation for all points is made in Table 4 . The mean values of the model with the adjusted empirical constants are much closer to 1 and $0 \mathrm{~dB}$ compared to the empirical constants originally applied (base). The noise level is underpredicted by an average of $1.8 \mathrm{~dB}$ instead of $9.6 \mathrm{~dB}$ which is a good improvement of about $8 \mathrm{~dB}$. 
Table 4 Arithmetic mean $\bar{f}$ and standard deviation $\sigma$ of the ratios shown in Fig. 11. The statistics distinguish between the calculations based on the empirical constants originally applied (base) and the adjusted constants (improved).

\begin{tabular}{|l|l|l|}
\hline & base & improved \\
\hline Turbulent intensity $f_{I}=I_{2} / I_{3}$ & & \\
\hline$\overline{f_{I}}$ & 0.56 & 1.11 \\
\hline$\sigma_{I}$ & 0.17 & 0.34 \\
\hline Turbulent length scale $f_{L}=L_{2} / L_{3}$ & & \\
\hline$\overline{f_{L}}$ & 0.68 & 1.03 \\
\hline$\sigma_{L}$ & 0.12 & 0.18 \\
\hline Noise level $f_{P}=\Delta \mathrm{OAPWL}$ & & \\
\hline$\overline{f_{P}}$ & $-9.6 \mathrm{~dB}$ & $-1.8 \mathrm{~dB}$ \\
\hline$\sigma_{P}$ & $3 \mathrm{~dB}$ & $3 \mathrm{~dB}$ \\
\hline
\end{tabular}

\section{Influence of flow phenomena in endwall regions on acoustics}

The adjustment of the empirical constants as described in the previous section improves the estimation of wake turbulence and consequently increases the accuracy of the broadband noise prediction from $10 \mathrm{~dB}$ to $2 \mathrm{~dB}$ approximately. But there are still cases which do not match perfectly with the RANS-based noise prediction. Additionally, the variance is unaffected by the adjustment of the constants and rather high with a standard deviation of $\sigma_{P}=3 \mathrm{~dB}$. Hence, there might be more influences on the acoustics that are not yet covered by the applied model. For example, tip leakage or endwall boundary layers might also increase the turbulence behind the rotor. Thus, the contribution of the flow in the hub and tip region to the noise results is considered in this section. In the end, we want to know if this contribution is negligible or we might end up with recommendations for adding hub and tip corrections to further increase the accuracy of noise predictions.

For this purpose, the RANS-informed mode is studied once again. An artificial removal of RANS simulated turbulence quantities in the hub and tip region is supposed to give an understanding of their respective contribution to the overall sound power. In practice, we reduce the steep slope of turbulence at the endwalls, as if the turbulence characteristics were unaffected by the endwalls. This procedure is applied to the hub region (called "no hub") and tip region (called "no tip") individually and in addition to both regions combined (called "no hub + no tip"). These altered radial evolutions of turbulent flow are then compared with the unaltered radial evolution (called "base"). Conceived in general terms, the noise estimation labeled with "no hub" for example characterizes the influence of the endwall flow in the hub region. The hub and tip regions are defined with a fixed spanwise domain for all configurations, respectively 0 to $20 \%$ span and 75 to $100 \%$ span. Figure 12 illustrates this approach for the NASA SDT fan during approach operation. The dimensionless quantities in the middle and right figure are not exactly constant in endwall regions due to slight variations of the meanflow velocity and chord length respectively. Therefore, the turbulent kinetic energy was plotted additionally in the left figure which illustrates the constant behavior adopted near the endwall for the "no hub + no tip" case.

For the NASA SDT fan, high-quality hot-wire measurements are available at approach conditions. Comparing the measurements with the RANS simulations, we observe a good agreement of the turbulent intensity and an underestimation of the turbulent length scale especially in the tip region. The radial average of the computed turbulence quantities are again plotted as dotted lines. The procedure of clipping the turbulence in the endwall region leads to a reduced turbulent intensity and slightly increased turbulent length scale since the RANS simulation predicts an increase of kinetic energy and a decrease of length scale at the endwalls.

As shown in Fig. 13, the broadband PSD spectrum is lower for the clipped "no hub + no tip" case than for the base, as expected. But also the unaltered RANS simulation leads to a lower PSD spectrum compared to the microphone measurements which is in accordance with the hot-wire measurements in Fig. 12 .

The procedure is again generalized to all considered cases and depicted in Fig. 14 A ratio of the turbulence quantities concerning the no-hub and no-tip cases and the combination of both compared to the unaltered base quantities is shown in the first two diagrams. The last diagram again shows the OAPWL difference between the no-hub- and 

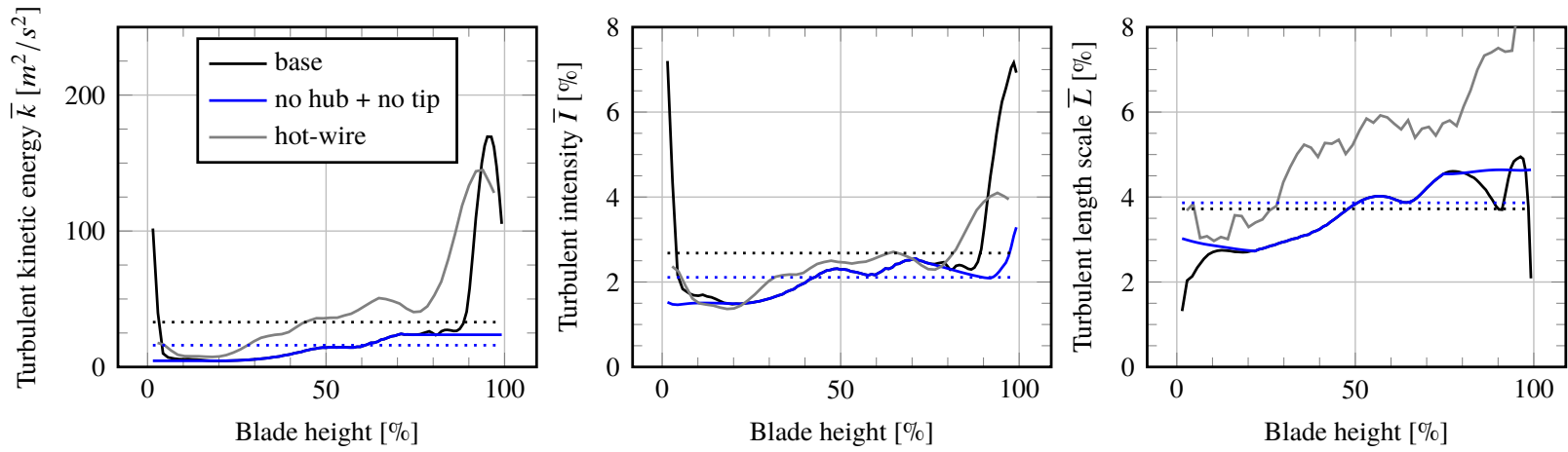

Fig. 12 Radial distribution (solid) and average (dotted) of the circumferentially averaged turbulence statistics, turbulent kinetic energy $\bar{k}$, turbulent intensity $\bar{I}$ and the normalized turbulent length scale $\bar{L}$, in the rotor wakes of the NASA SDT fan for approach operation. The blue color indicates the calculated turbulence quantities with clipped turbulence in the endwall regions.

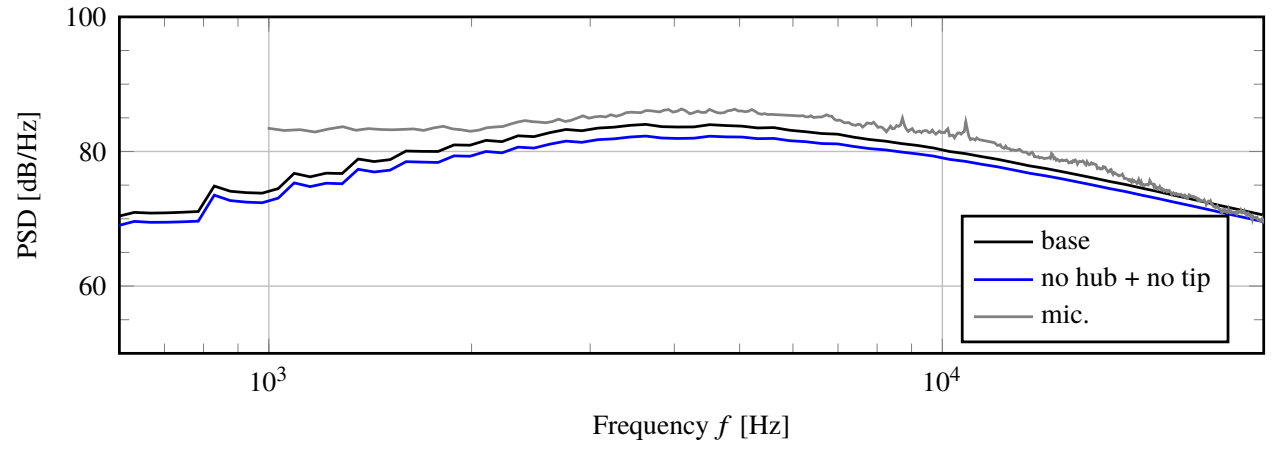

Fig. 13 Section of the broadband power spectral density (PSD) for wake interaction noise source of the NASA SDT fan for approach operation compared to microphone measurements. The blue color indicates the calculated spectrum with clipped turbulence in the endwall regions.

no-tip-approaches on the one side and the unaltered base on the other side. A value of 1 or $0 \mathrm{~dB}$ corresponds to no influence of the endwall-flow turbulence in the equivalent regions. In general, the turbulent intensity of the clipped radial evolution is smaller than the base one, supporting the idea that additional turbulence is produced near the endwalls on top of the mid-span region. Concerning the turbulent length scale, there is no clear difference, in average, between the endwall regions and the mid-span regions. Owing to the increased turbulence near the endwalls, the sound power contribution of these regions amounts up to $2 \mathrm{~dB}$ to the overall sound power. Additionally, the diagrams show that in some cases the contribution from the hub is higher than that from the tip. But the tip region dominates for most of the cases. Besides, some special cases can be identified: ACAT-SG-LN-AP and ASPIRE-SL show almost no difference of turbulent intensity compared to the unaltered turbulence. This is caused by wavy characteristics of the turbulent intensity in the endwall regions where peaks and valleys result in a similar value in average. ACAT-CB and ACAT-SL (LN as well as SLS working lines) show almost no tip influence but a strong hub influence of the turbulence on the noise prediction. The RANS simulations for these cases predict strong turbulence in the hub region but the reason for that is not clear to the authors.

Those findings can be summarized and quantified by the arithmetic means and standard deviations listed in Table 5 The average of all cases shows that the contribution to noise is small concerning the flow in the hub region and bigger for the tip region. This might be caused by the increased turbulence in the tip region due to flow phenomena like separation or tip vortex and the more important area-weighting of the tip region. The "no hub + no tip" values are understandably the sum of the individual no-hub- and no-tip-cases.

Summarizing these findings we can state that the tip region experiences increased turbulence intensity levels due to endwall flow, which explains that neglecting this effect underestimates the overall sound power by 1 to $2 \mathrm{~dB}$. The 

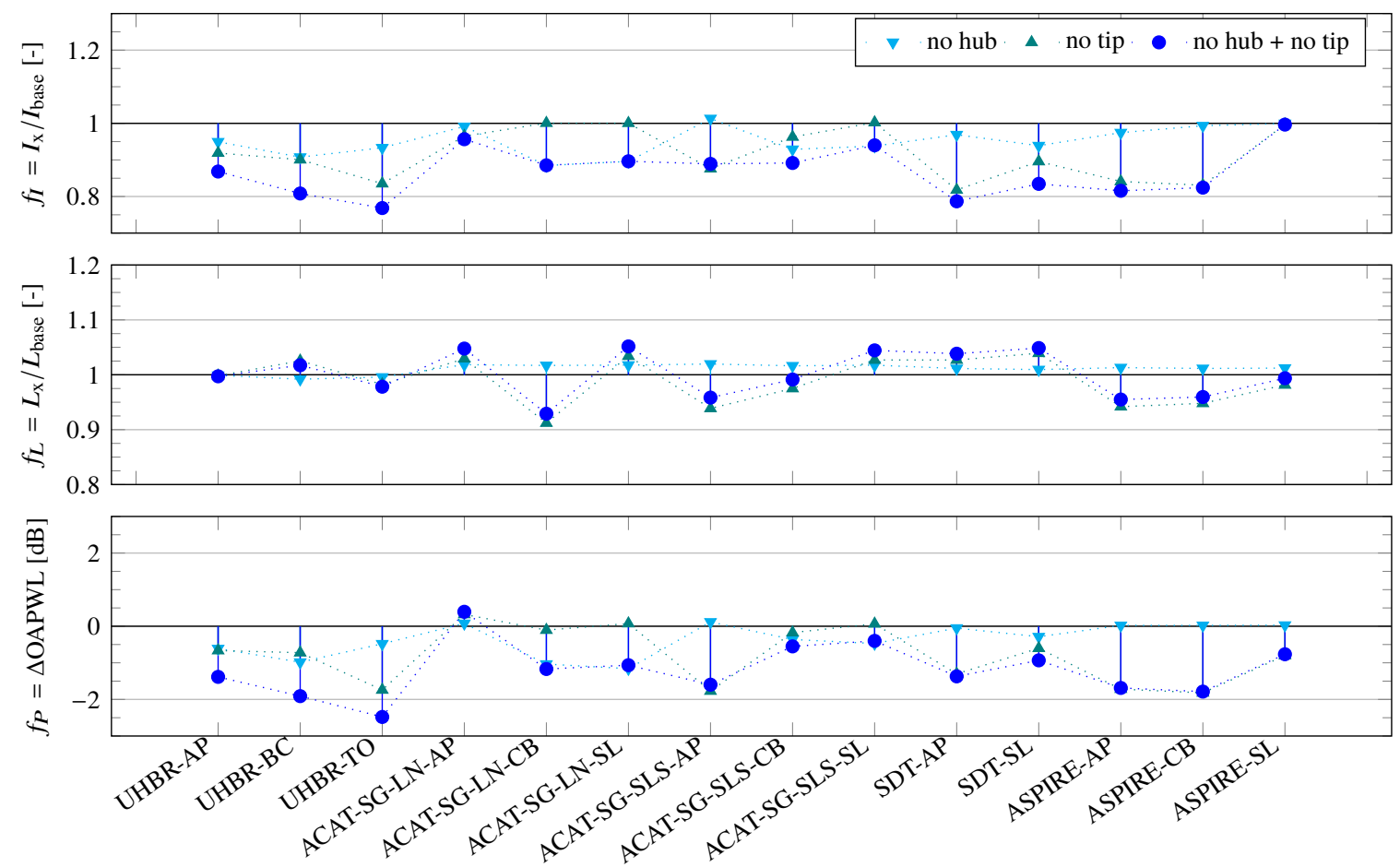

Fig. 14 Ratio of the turbulence quantities and difference between the OAPWL values comparing the clipped turbulence with the unaltered case (base) for all considered points. The blue color (circular mark) indicates the cases with clipped turbulence in the endwall regions. The other two colors (triangular marks) each indicate the clipping of the hub and tip region only.

Table 5 Arithmetic mean $\bar{f}$ and standard deviation $\sigma$ of the ratios shown in Fig. 14. The statistics distinguish between the clipped turbulence in the hub region (no hub), tip region (no tip) and both regions (no hub + no tip) compared to the unaltered case (base).

\begin{tabular}{|l|l|l|l|}
\hline & no hub & no tip & no hub + no tip \\
\hline Turbulent intensity $f_{I}=I_{x} / I_{\text {base }}$ & & & \\
\hline$\overline{f_{I}}$ & 0.95 & 0.92 & 0.87 \\
\hline$\sigma_{I}$ & 0.04 & 0.07 & 0.06 \\
\hline Turbulent length scale $f_{L}=L_{x} / L_{\text {base }}$ & & & \\
\hline$\overline{f_{L}}$ & 1.01 & 0.99 & 1.0 \\
\hline$\sigma_{L}$ & 0.01 & 0.04 & 0.04 \\
\hline Noise level $f_{P}=\Delta$ OAPWL & & & \\
\hline$\overline{f_{P}}$ & $-0.4 \mathrm{~dB}$ & $-0.8 \mathrm{~dB}$ & $-1.2 \mathrm{~dB}$ \\
\hline$\sigma_{P}$ & $0.4 \mathrm{~dB}$ & $0.7 \mathrm{~dB}$ & $0.7 \mathrm{~dB}$ \\
\hline
\end{tabular}

influence of the hub region is less important but could also contribute by up to $1 \mathrm{~dB}$ in certain cases. Taking the measurements into account, the contribution could be even more. The share of the endwall regions exhibit a rather high variance with a standard deviation of $\sigma_{P}=0.7 \mathrm{~dB}$. Thus, it is quite difficult to make a general suggestion because the endwall turbulence characteristics are very diversified from operating point to operating point. However, it would be beneficial to incorporate a modification to the model that covers the turbulence interaction with the OGV in the endwall regions apart from the mid-span wake turbulence. 


\section{Conclusion}

Fan broadband interaction noise is mainly caused by the excitation of the OGV due to the turbulence in the wakes generated by the rotor. In this paper, a wake turbulence model based on the literature was presented and investigated on a number of fans and operating conditions. The model is partly empirical and it provides the necessary turbulence for an analytical acoustic model for the noise prediction. Hence, the quality of the noise prediction depends on the steady aerodynamic input for the turbulence model (mainly the pressure loss of the rotor in this case), the unsteady aerodynamic input for the acoustic model (the wake turbulence quantities in this case), and the acoustic model itself.

A first appraisal of the estimation of turbulence based on pre-design flow parameters and comparison to computational calculation of turbulence showed some strengths and weaknesses of these models. It was shown that the pressure loss is quite well evaluated by the meanline and throughflow methods when compared to a RANS simulation. Additionally, the assumption of the correlation between loss and turbulence seemed acceptable. But it was necessary to recalibrate the model in order to achieve a better estimation of the wake turbulence for the investigated cases. The empirical constant for the estimation of turbulent kinetic energy was increased from $K_{U}=0.3$ to 0.6 and the constant for the estimation of integral turbulent length scale was increased from $K_{L}=0.2$ to 0.3 . With this improvement the broadband fan interaction noise is now underestimated by approximately $2 \mathrm{~dB}$ instead of $10 \mathrm{~dB}$.

However, the broadband noise estimation still exhibits an uncertainty because the predicted noise level difference varies from case to case in an average range of $\pm 3 \mathrm{~dB}$. Therefore, we investigated more on other effects influencing the noise prediction than the meanline wake turbulence. The turbulence in the endwall regions obtained from RANS simulations was identified to contribute by approximately $1 \mathrm{~dB}$ in average. But again the uncertainty was rather high since the contribution could change from case to case in an average range of $\pm 0.7 \mathrm{~dB}$. In other words, neglecting the endwall-specific turbulence may in some cases not change the overall sound power at all but it may in other cases underestimate it by up to $2 \mathrm{~dB}$. Nevertheless, it would be reasonable to explore this topic further.

For the moment, we see three possible solutions that could improve the broadband noise prediction: First, a tailored calibration of the constants $K_{U}$ and $K_{L}$ for the turbulence in the endwall regions would be a simple solution to improve the results when using the $2 \mathrm{D}$ input from the throughflow solver. But this approach is not supposed to be promising since the assumed proportional correlation in the model does not seem to apply to endwall regions as the rather high standard deviations in Table 3 indicate. Second, the identification of the exact flow phenomena in the hub and tip region would help to establish new turbulence models which could be based upon other loss components like endwall loss. This would be relevant for the application with the 1D meanline and 2D throughflow-informed modes. And third, the investigation on and consideration of background turbulence could improve the overall estimation of turbulence.

Of course, there are more possible sources of errors that could influence the noise prediction. The models could comprise more missing parts than explored in this paper like the calculation of the mean wakes. Additionally, we make some simplifications for the methods when we derive the viscous loss from the overall loss and investigated the turbulence in the endwall region by clipping the RANS data. In the end, we assume that an extension of the model by the endwall effects as well as background turbulence could improve the model and the application of the throughflow method to more fans and operating points could generate more reliable data.

\section{Acknowledgments}

The presented work was partly conducted in the frame of the DLR internal project PERFECT. In this context, the authors are thankful for the technical support from the Engine Department (DLR Institute of Propulsion Technology) and for the provision of the throughflow calculations from the Fan and Compressor Department (DLR Institute of Propulsion Technology). Additionally, the authors are grateful for the RANS simulations and the processing of the measurements by our colleagues of the Engine Acoustics Department (DLR Institute of Propulsion Technology).

\section{References}

[1] Dunham, J., "Modelling of spanwise mixing in compressor through-flow computations," Proceedings of the Institution of Mechanical Engineers, Part A: Journal of Power and Energy, Vol. 211, No. 3, 1997, pp. 243-251. https://doi.org/10.1243/ 0957650971537150, URL http://journals.sagepub.com/doi/10.1243/0957650971537150

[2] Calvert, W. J., and Ginder, R. B., "Transonic fan and compressor design," Proceedings of the Institution of Mechanical Engineers, Part C: Journal of Mechanical Engineering Science, Vol. 213, No. 5, 1999, pp. 419-436. https://doi.org/10.1243/ 0954406991522671, URL http://journals.sagepub.com/doi/10.1243/0954406991522671 
[3] Casey, M., and Robinson, C., "A new streamline curvature throughflow method for radial turbomachinery," Journal of Turbomachinery, Vol. 132, No. 3, 2010, p. 10. https://doi.org/10.1115/1.3151601, URL https://turbomachinery.asmedigitalcollection. asme.org/article.aspx?articleID=1468211

[4] Adkins, G. G., and Smith, L. H., "Spanwise mixing in axial-flow turbomachines," Journal of Engineering for Power, Vol. 104, ASME, Houston, Texas, USA, 1982, pp. 97-110. https://doi.org/10.1115/1.3227271, URL http://gasturbinespower. asmedigitalcollection.asme.org/article.aspx?articleid=1420405

[5] Dubitsky, O., Wiedermann, A., Nakano, T., and Perera, J., "The reduced order through-flow modeling of axial turbomachinery," Proceedings of the International Gas Turbine Congress, 2003, p. 8. URL https://www.researchgate.net/publication/252878403_ The_Reduced_Order_Through-Flow_Modeling_of_Axial_Turbomachinery

[6] Schnoes, M., and Nicke, E., "Automated calibration of compressor loss and deviation correlations," Volume 2A: Turbomachinery, ASME, Montreal, Quebec, Canada, 2015, p. 13. https://doi.org/10.1115/GT2015-42644. URL http: //proceedings.asmedigitalcollection.asme.org/proceeding.aspx?doi=10.1115/GT2015-42644

[7] Dunham, J., “A new endwall model for axial compressor throughflow calculations," Journal of Turbomachinery, Vol. 117, ASME, The Hague, Netherlands, 1995, pp. 533-540. https://doi.org/10.1115/94-GT-075. URL http://proceedings.asmedigitalcollection. asme.org/proceeding. aspx?articleid=2143533

[8] Gallimore, S. J., "Axial flow compressor design," Proceedings of the Institution of Mechanical Engineers, Part C: Journal of Mechanical Engineering Science, Vol. 213, No. 5, 1999, pp. 437-449. https://doi.org/10.1243/0954406991522680, URL http://journals.sagepub.com/doi/10.1243/0954406991522680

[9] Banjac, M., Petrovic, M. V., and Wiedermann, A., "Secondary flows, endwall effects and stall detection in axial compressor design," Journal of Turbomachinery, Vol. 137, No. 5, 2015, p. 12. https://doi.org/10.1115/1.4028648 URL http://turbomachinery. asmedigitalcollection.asme.org/article.aspx?articleid=1910251

[10] Amiet, R. K., "High frequency thin-airfoil theory for subsonic flow," AIAA Journal, Vol. 14, No. 8, 1976, pp. $1076-1082$. https://doi.org/10.2514/3.7187. URL http://arc.aiaa.org/doi/10.2514/3.7187

[11] Moreau, A., "A unified analytical approach for the acoustic conceptual design of fans of modern aero-engines," Doctoral Thesis, Technische Universität Berlin, Berlin, Jul. 2016. URL http://dx.doi.org/10.14279/depositonce-5935

[12] Vieweg, M., Reitenbach, S., Hollmann, C., Schnös, M., Behrendt, T., Krumme, A., Otten, T., and Meier zu Ummeln, R., "Collaborative aircraft engine preliminary design using a virtual engine platform, part B: Application," AIAA Scitech 2020 Forum, American Institute of Aeronautics and Astronautics, Orlando, FL, USA, 2020, p. 16. https://doi.org/10.2514/6.2020-0124 URL https://arc.aiaa.org/doi/10.2514/6.2020-0124

[13] Jaron, R., “Aeroakustische Auslegung von Triebwerksfans mittels multidisziplinärer Optimierungen,” Doctoral Thesis, Technische Universität Berlin, Berlin, May 2018. URL http://dx.doi.org/10.14279/depositonce-7057.

[14] Kaplan, B., "Design of an advanced fan stage with ultra high bypass ratio and comparison with experimental results," Doctoral Thesis, Ruhr-Universität Bochum, Cologne, Apr. 2010. URL https://elib.dlr.de/65013/.

[15] Meier zu Ummeln, R., and Moreau, A., "Eine Methode zur schnellen Fanlärmberechnung basierend auf einem aerodynamischen Mehrschnittverfahren,” DAGA 2019 - 45. Jahrestagung für Akustik, DEGA, Rostock, 2019, pp. 319-322. URL https: //elib.dlr.de/126991/

[16] Ganz, U. W., Joppa, P. D., Patten, T. J., and Scharpf, D. F., "Boeing 18-inch fan rig broadband noise test," Technical Report NASA/CR-1998-208704, Boeing Commercial Airplane Group, Hampton, Virginia, USA, Sep. 1998. URL https: //ntrs.nasa.gov/search.jsp?R=19980236567

[17] Wygnanski, I., Champagne, F., and Marasli, B., "On the large-scale structures in two-dimensional, small-deficit, turbulent wakes," Journal of Fluid Mechanics, Vol. 168, 1986, pp. 31-47. https://doi.org/10.1017/S0022112086000289. URL http://www.journals.cambridge.org/abstract_S0022112086000289

[18] Camp, T. R., and Shin, H.-W., "Turbulence intensity and length scale measurements in multistage compressors," Journal of Turbomachinery, Vol. 117, No. 1, 1995, pp. 38-46. https://doi.org/10.1115/1.2835642. URL https://doi.org/10.1115/1.2835642

[19] Jurdic, V., Joseph, P., and Antoni, J., "Investigation of rotor wake turbulence through cyclostationary spectral analysis," AIAA Journal, Vol. 47, No. 9, 2009, pp. 2022-2030. https://doi.org/10.2514/1.36728. URL https://arc.aiaa.org/doi/10.2514/1.36728 
[20] Lieblein, S., "Loss and stall analysis of compressor cascades," Journal of Basic Engineering, Vol. 81, No. 3, 1959 , pp. $387-397$. https://doi.org/10.1115/1.4008481, URL https://doi.org/10.1115/1.4008481

[21] Kaplan, B., Nicke, E., and Voss, C., "Design of a highly efficient low-noise fan for ultra-high bypass engines," Volume 6: Turbomachinery, Parts A and B, Turbo Expo: Power for Land, Sea, and Air, Vol. Volume 6: Turbomachinery, Parts A and B, ASME, Barcelona, Spain, 2006, pp. 185-194. https://doi.org/10.1115/GT2006-90363. URL/https://doi.org/10.1115/GT200690363

[22] Meillard, L., Schnell, R., Meyer, R., and Voigt, C., "Time resolved pressure and velocity measurements at the DLR UHBR-fan and comparison with simulation data," 62. Deutscher Luft- und Raumfahrtkongress, DGLR, Stuttgart, 2013, p. 13. URL https://elib.dlr.de/85521/

[23] Schnell, R., Giebmanns, A., Nicke, E., and Dabrock, T., "Aerodynamic analysis of a fan for future ultra-high-bypass-ratio aeroengines," 19th ISABE Conference, International Symposium on Air Breathing Engines, Vol. 1, American Institute of Aeronautics and Astronautics, Montreal, Canada, 2009, pp. 400-409. URL https://elib.dlr.de/63554/.

[24] Kissner, C. A., Guerin, S., and Behn, M., "Assessment of a 2D synthetic turbulence method for predicting the ACAT1 fan's broadband noise," 25th AIAA/CEAS Aeroacoustics Conference, American Institute of Aeronautics and Astronautics, Delft, The Netherlands, 2019, p. 22. https://doi.org/10.2514/6.2019-2501. URL https://arc.aiaa.org/doi/10.2514/6.2019-2501

[25] Guerin, S., Kissner, C. A., Kajasa, B., Jaron, R., Behn, M., Pardowitz, B., Tapken, U., Hakansson, S., Meyer, R., and Enghardt, L., "Noise prediction of the ACAT1 fan with a RANS-informed analytical method: success and challenge," 25th AIAA/CEAS Aeroacoustics Conference, American Institute of Aeronautics and Astronautics, Delft, The Netherlands, 2019 , p. 27. https://doi.org/10.2514/6.2019-2500 URL https://arc.aiaa.org/doi/10.2514/6.2019-2500

[26] Tweedt, D. L., "Preliminary aerodynamic investigation of fan rotor blade morphing," Final Contractor Report NASA/CR-2012217815, AP Solutions, Inc., Cleveland, Ohio, USA, Dec. 2012. URL https://ntrs.nasa.gov/search.jsp?R=20130001702.

[27] Woodward, R., Hughes, C., Jeracki, R., and Miller, C., "Fan noise source diagnostic test - Far-field acoustic results," 8th AIAA/CEAS Aeroacoustics Conference \& Exhibit, American Institute of Aeronautics and Astronautics, Breckenridge, Colorado, USA, 2002, p. 26. https://doi.org/10.2514/6.2002-2427/ URL http://arc.aiaa.org/doi/abs/10.2514/6.2002-2427

[28] Envia, E., Tweedt, D., Woodward, R., Elliott, D., Fite, E., Hughes, C., Podboy, G., and Sutliff, D., "An assessment of current fan noise prediction capability," 14th AIAA/CEAS Aeroacoustics Conference (29th AIAA Aeroacoustics Conference), American Institute of Aeronautics and Astronautics, Vancouver, British Columbia, Canada, 2008, p. 46. https://doi.org/10.2514/6.20082991 URL http://arc.aiaa.org/doi/10.2514/6.2008-2991

[29] Podboy, G., Krupar, M., Hughes, C., and Woodward, R., "Fan noise source diagnostic test - LDV measured flow field results," 8th AIAA/CEAS Aeroacoustics Conference \& Exhibit, American Institute of Aeronautics and Astronautics, Breckenridge, Colorado, USA, 2002, p. 28. https://doi.org/10.2514/6.2002-2431. URL http://arc.aiaa.org/doi/abs/10.2514/6.2002-2431.

[30] Schnell, R., Goldhahn, E., and Julian, M., "Design and performance of a low fan-pressure-ratio propulsion system," 24th ISABE Conference, Canberra, Australia, 2019, p. 15.

[31] Kissner, C. A., and Guérin, S., "Influence of wake and background turbulence on predicted fan broadband noise," AIAA Journal, 2019, p. 14. https://doi.org/10.2514/1.J058148. URL/https://arc.aiaa.org/doi/10.2514/1.J058148

[32] Schnoes, M., Voß, C., and Nicke, E., "Design optimization of a multi-stage axial compressor using throughflow and a database of optimal airfoils," Journal of the Global Power and Propulsion Society, Vol. 2, 2018, pp. 516-528. https: //doi.org/10.22261/JGPPS.W5N91I URL https://journal.gpps.global/a/W5N91I

[33] Marciniak, V., Weber, A., and Geler, E. K., "Modelling transition for the design of modern axial turbomachines," 11th World Congress on Computational Mechanics (WCCM XI), 6th European Conference on Computational Fluid Dynamics (ECFD VI), 2014, p. 13. URL http://www.wccm-eccm-ecfd2014.org/

[34] Jaron, R., Herthum, H., Franke, M., Moreau, A., and Guérin, S., "Impact of turbulence models on RANS-informed prediction of fan broadband interaction noise," European Conference on Turbomachinery Fluid Dynamics and hermodynamics, Stockholm, Sweden, 2017, p. 13. https://doi.org/10.29008/ETC2017-067 URL https://doi.org/10.29008/ETC2017-067.

[35] Denton, J. D., "Loss Mechanisms in Turbomachines," Journal of Turbomachinery, Vol. 115, No. 4, 1993 , pp. $621-656$. https://doi.org/10.1115/1.2929299. URL http://turbomachinery.asmedigitalcollection.asme.org/article.aspx?articleid=1464386 